\title{
EFFICACY OF COLLABORATIVE IN IMPROVING LEARNING OUTCOMES OF GRAPHIC DESIGN IN HIGHER EDUCATION
}

\author{
O. A. Ojo* \\ Department of Design and Studio Art \\ e-mail: oojo@cut.ac.za
}

\author{
I. M. Ntshoe* \\ Innovation in Learning and Teaching \\ e-mail: intshoe@cut.ac.za \\ ${ }^{*}$ Central University of Technology \\ Bloemfontein, Free State
}

\section{ABSTRACT}

This article presents collaborative design projects done by 28 second-year graphic design students. These projects were identified by the lecturer to be examples of 'real' world and 'handson' projects that are complex, challenging enough and could be impossible for an individual student to complete alone within the limited time frame. These projects not only require students to synthesise their work in a true collaboration, but also to complete work separately and turn it in together at the end. What set these collaborative design projects apart from other graphic design projects are the adept outcome and the amount of control that the students are given over the design.

Keywords: design education, collaborative design, visual communication, real-world project, collaboration

\section{INTRODUCTION}

Graphic design students, like many other students in the practical orientated disciplines such as engineering, medicine, architecture and others, need collaborative skills and experience in order to survive the labour market in the current global economy. However, for most design courses taught at a university of technology level, it is difficult always to provide a 'real world' professional practice experience at an undergraduate level. In addition, this learning area requires a challenge that opens the door for the learner actively to engage his/her peers and to process and merge information and create products rather than simply memorise and recite it. One of the means of gaining the necessary experience in this regards is to expose students to as many collaborative projects as possible while studying as directed by their curricula (SAQA 2005). In such cases, the necessary knowledge and skills will be transferred to the learners. 
The lecturer identified the project to be examples of those 'real' world and 'hands-on' projects that are complex, challenging enough and could be impossible for an individual student to complete alone within the limited time at hand. Not only that, these projects require students to synthesise their work in true collaboration, rather than just complete work separately and turn it in together at the end. However, collaborative learning in practical based programmes, is not always easy to manage.

Therefore, the aim of this study is to evaluate the effectiveness of collaborative learning in graphic design education and the findings could contribute to the knowledge of teaching and learning in graphic design and using collaborative learning to improve the learning outcomes.

The thrust of this study is on teaching and learning of graphic design in a university of technology. This study used the method of collaborative learning to improve learning outcomes.

\section{PROJECT OBJECTIVES}

This study has been carried out to evaluate the effectiveness of a collaborative project for improving learning outcomes amongst the graphic design students at a university of technology. Within the principal aim are the following objectives:

- To establish the significance of working within a group for a common goal

- To explore the effectiveness of collaborative learning in graphic design studies.

\section{CONCEPTUALISATION OF COLLABORATIVE LEARNING}

Collaborative learning is an educational method used in teaching and learning environments, which involves two or more people in groups working together to learn, solve a problem, complete a task, evaluate one another's ideas or create a product (Bruffee 1993; Dillenbourg 1999; Chiu 2008). Gerlach (1994) described collaborative learning as a naturally social act in which the participants talk among themselves and learn through the talk. Smith (1996) and MacGregor (1990) explain that, learning is an active process whereby students learn and relate views on new knowledge to a framework of prior knowledge. They further argue that, in the collaborative learning environment, the learners are challenged both socially and emotionally as they listen to different perceptions and are required to articulate and defend their ideas. In so doing, the learners begin to create their own unique conceptual frameworks and not rely exclusively on lecturer's or a text's framework. Consequently, learners in this learning approach, have the opportunity to discuss with peers, present and defend ideas, exchange different viewpoints, question other conceptual frameworks and be actively engaged (MacGregor 1990). 
This learning approach is appropriate to a graphic design learning environment approach and forms part of different learning methods used for facilitation in this learning area. In order words, learners engaged in collaborative learning by benefitting from one another's strength, technique and ability. By asking one another for information, critiquing one another's ideas, monitoring one another's work and helping weaker ones to learn (Chiu 2000; Chiu 2008). Therefore, one of the objectives of collaborative projects in graphic design study is to teach students to draw on the skills and abilities of each member of a group and learn.

Collaborative learning amongst students from different field of studies including Mathematics, English and Statistics are previously found to be effective (Forrester and Tashchian 2010). Some researchers found that it enables a higher level of achievement by all participant as opposed to an individual, competitive system in which many students are left behind (Slavin 1987; Forrester and Tashchian 2010). Enerson, Johnson, Milner and Plank (1997) also found that collaborative learning provides the opportunity for personal feedback and promotes exchanges of idea amongst students in small groups. Therefore, students receive more individual feedback about their ideas and responses. This feedback is often impossible in a large group or class. This learning method was found to engage students actively in learning, where each member is given opportunities to contribute in small groups.

Moreover, Kagan (1986) and Enerson et al. (1997) were of the opinion that individual projects promote competition and foster a win or lose situation, whereby superior students reap all the rewards and the weaker students reap none. In a collaborative learning environment, students help each other and in doing so, build a supportive learning group, which elevates the performance level of the individual member of the group.

\section{The research question is}

- What kind of learning outcomes will take place using a collaborative project method of facilitation amongst graphic design students?

\section{METHODOLOGY AND PROCEDURES}

\section{Course description}

Design Techniques II (DET20AK) is one of the core subjects in the programme of Diploma in Graphic Design at the university of technology. This subject provides basic practical knowledge in graphic design study. Individually, during the first semester, all the enrolled students in this subject examined the way visual language such as type, colour, imagery, texture and shape can 
be used to convey ideas, information and messages in the fields of visual communication. The individual project allowed them to practice and sharpened their drawing as the primary component of visual language to support the conceptualisation and visualisation of ideas.

Moreover, the students were introduced to techniques that will allow them to investigate, develop the skills to manipulate and organise design elements, design principles, selected media, materials and production methods when creating visual communication materials. In addition, throughout the semester students explored manual and digital methods to develop and refine visual materials. One can say, to an extent, with individual practice, students gained confidence in using visual language and are supported to reflect on and critique their own and others' visual communication projects.

\section{Design and procedure}

The learning in this module was organised as a sequence of two phases. Each phase has different tasks with an assessment and feedback at the end of each segment as recommended by Francescato, Porcelli, Mebane, Cuddetta, Klobas and Renzi (2006). The lecturer took the precaution of not over assessing the projects. With this method, the learning process was defined and monitored by the subject lecturer. To confirm that all the students have been taught the necessary skills and that they are all exposed to basic principles and techniques in graphic design, they were all briefed at the same time and instructed to come up with their concepts individually.

At each stage of the projects, students were presented with an opportunity to learn from one another. When faced with challenges, students were prompted to ask questions. The lecturer was available to give directions, instructions and demonstrations where necessary. This gave the students the opportunity to test their ideas, take risks and be creative.

Furthermore, an exhibition has been announced for the exposure of the finished products. The academic credibility of the programme head, the lecturer in charge of the subject and thrust of the funding unit were all at stake. These risks conform to the normal risks in the design industry, where the aim of every project is to be successful and effective. The expectations associated with these projects encouraged the students take the opportunity and actively participate.

\section{Sampling}

Purposeful sampling method was used to distribute 28 second-year students enrolled in Design Techniques II (DET20AK) into groups. Two of these students dropped out. The remaining 26 
participants consist of 15 male and 11 female students with ages ranging between 19 and 25 . The mean is 22 years. The students were divided into four groups; two groups with six members each, the other two groups with seven members each. Four students were seeded, based on their strengths and abilities in the prior learning in this subject during the previous semester as well as in the preliminary phase of this project (Enerson et al. 1997). The remaining five or six group members of each group were selected through a ballot system and grouped with each of the four seeded students. Which means two of the groups is constituted by seven members while the remaining two groups have six members each. This selection system was used because the learners shared the same background knowledge and the nature of the projects need a mix of background experience, abilities, work styles and learning methods as suggested by Enerson et al. (1997). The group sizes were basically determined by the amount of work the projects required.

Initially when the brief was given, students were under the impression that they will selfselect their groups. However, the moment they were informed about the lecturer's decision not to allow them to self-select their group members they were upset and questioned the success of the project. The lecturer thought the project was an extensive learning activity and the learning objective would not be achieved if the students were allowed to self-select their groups. As Enerson et al. (1997) explained, students who choose to work with friends often have a harder time with group projects than students do in groups chosen by the lecturer. The lecturer wanted the individuals to create opportunities to learn within groups.

\section{PHASE 1 OF THE PROJECT}

\section{Task 1}

This task required the skill and knowledge acquired in prior classes about conceptualisation and development of ideas. Each student researched the topic and proceeded to brainstorm by using the concept of mind mapping to produce three sketches each. These sketches were mounted for a critique session; the lecturer gave feedback and advice to improve on the sketches. Peers and the lecturer presented final sketches for assessment.

\section{Task 2}

Students built their mock-ups individually using papers, cardboards and different soft or flexible inexpensive materials. These mock-ups were then presented in the design studio for a critique and feedback session. Each student was advised to proceed to making prototypes and 
presenting them for evaluations.

This time, the evaluations of task 2 were done collaboratively using a jigsaw method. Choe (2001) highlights that the jigsaw method encourages full engagement and understanding of each member of the group in the academic activity in which they are involved. This exercise requires that the students be selected randomly into groups of five by the lecturer to assemble the mockups into different categories. They are asked to consider the design idea, functionality of the products, basic design features, design elements, visual harmony and aesthetic appearance. They also consider the technical excellence of each mock-up such as colour, texture, accuracy and neatness. These student assessors were asked to categorise the works according to their preferences considering the theme of the project as well as the guidelines set out in the brief.

The first set of five student assessors identified the dynamics of the design solutions presented by their colleagues and arranged the prototypes into four different categories based on the quality of the works in terms of creativity, technical structures and presentations as instructed.

The second set of five student assessors were given the mandate to evaluate what the first set had done - if they concur with their assessments or not. They made adjustments by regrouping some of the works into more appropriate categories.

The third set of student assessors also gave their input and the lecturer fine-tuned the process and allocated marks with the use of the rubric that was given to the students when they were briefed. Each of the best four prototypes out of the twenty-six prototypes was adopted as the working mock-up model for each group’s collaborative work.

\section{PHASE 2 OF THE PROJECT}

\section{Task 1}

Each group was given permission to considerably improve or modify their adopted models where necessary. They were instructed to proceed and present their final prototype with the estimation of material needed, work plan (that is, discussing who was going to do what and when) and work-in-progress meeting schedules. These documents were used by the lecturer to provide the materials needed for each group project from the fund provided by the Advance Marketing Unit of the institution. The documents also helped the lecturer to monitor the process and the progress of the learning activities taking place. 


\section{Task 2}

This segment was the final phase of the projects took place and different technical learning took place. It also involved some risks, such as wasting of resources given for the implementation of the project, as well as the risk of failure.

In addition, this part of the project afforded the participants the opportunity to learn about magnification and scaling. They also have 'hands on' experience in handling of delicate materials such as cutting of vinyl and perspex with a laser-cutting machine. Their experience and level of competencies in generating concepts on computer, actualising their concepts, calculations, measuring and pasting of vinyl were among the exercises they were involved in during this segment of the project.

What set this collaborative project apart from other graphic design projects are the professional outcomes and the amount of control that the students are given over the projects. A project of this level is something not many graphics design students would have a chance to produce or be part of while still learning and with the support of the Advance Marketing Unit of our institution is a very valuable experience. The unit provided all the materials used for this project and thus made it possible for the completion and delivery of the finished products within the time limit.

A multiple assessment method (Enerson et al. 1997) was used for the final assessment of the group projects. The projects were measured against different criteria, which includes process and product. The final group products constituted 80 per cent of the marks while the remaining 20 per cent was reserved for the individual efforts during the preliminary work in phase 1. This assessment method was used to ensure that the weaker students did not drag the stronger students down.

\section{INSTRUMENT}

Questionnaires were used to collect data for the study. The respondents were asked to respond to a set of questionnaires that was adopted from Cantwell and Andrews (2002). Participants completed 19 questions regarding inventory-measuring preferences, feelings, competencies and attitudes toward group work. In the first part, the respondents' responses are ranked on a Likert scale of (1) to (4). The reason for using a four-point Likert scale is that the researcher was measuring efficacy and a neutral response will not measure what it set out to measure as suggested by Garland (1991). Lozano, Garcia-Cueto and Muniz (2008) also found that the minimum number of categories for ensuring an appropriate level of reliability is four, while the maximum number could be seven. Another reason is that the respondents need to make a 
definite choice rather than chose neutral or intermediate positions on a scale. This helped the respondents to specify their level of agreement or disagreement on a symmetric of strongly agree - strongly disagree scale for a series of statements. This rating system captures the intensity of their feelings for a given statement or question. That is, (1) in this case indicates strongly agree, (2) agree, (3) disagree, and (4) strongly disagree. In the second part, they were asked to respond to a series of questions about the projects as well as their reflections on every stage of the process.

\section{RESULTS}

The results of this study are broken down into four parts. The first part reports the results of questions 1 to 8 and second part reports results of questions 9 to 16 . The third part reflects the results of questions 17 to 21. Part four reports results from semi-structured interview (questions 22 to 24). The participants were asked to reflect and comment on their learning experience.

Q1. Working in pairs and groups on real world project like this should be encouraged

Q2. Helped developing generic skills amongst the participants

Q3. Fostered exchanged of knowledge, information and design techniques

Q4. Made problem solving easier

Q.5 Received useful and helpful feedback from the lecturer

Q6. Got fresh insight on how to work neatly and creatively

Q7. Got a new perspective of using two or more software applications together to produce the required results

Q8. Focused on collective efforts rather than individual effort

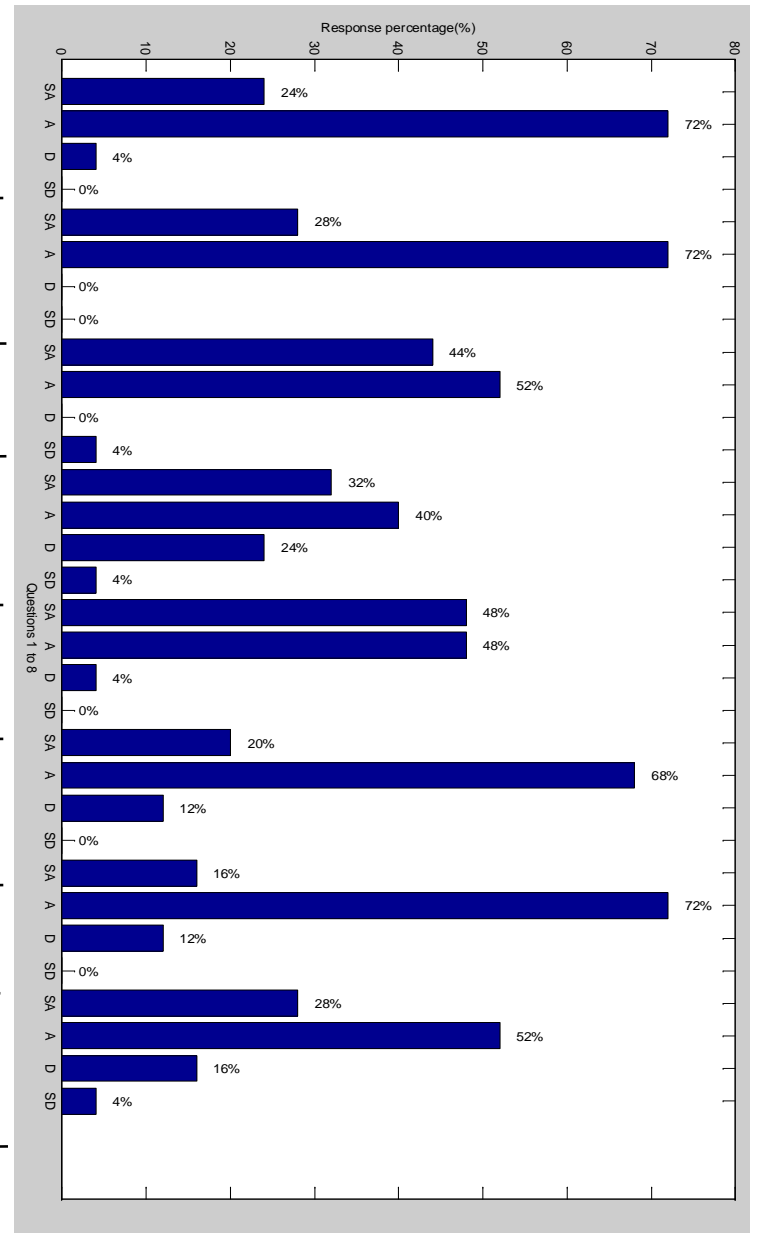

Figure 1: The results of part one (questions 1 to 8 ) 
The results of question 1 show a significant number of students believed that working in pairs and groups on a real world project like this should be encouraged. Twenty-four per cent strongly agree and 72 per cent agree, while $<1$ per cent strongly disagree and 4 per cent disagree respectively. The results of question 2 show a significant number of students believed that the project availed them the opportunity to learn general and simple skills from their peers.

Question 3 reflects the view of those who agree and disagree if group works promote exchange of knowledge. The respondents who strongly agree are 44 per cent and 53 per cent agree while 4 per cent of the respondents strongly disagree and $<1$ per cent disagree that collaboration fostered exchange of knowledge. Additionally, the project presented to them opportunity to learn different techniques their group members use to solve design problems. 32 per cent strongly agree and 40 per cent agree while 4 per cent strongly disagree and 24 per cent disagree that group works made problem solving easier. Furthermore, question 5 results show that 48 per cent of the respondents strongly agree and 48 per cent agree while $<1$ per cent strongly disagree and 4 per cent disagree that they received helpful feedback from the lecturer. In addition, in responding to question 6, 20 per cent strongly agree and 68 per cent agree while $<1$ per cent strongly disagree and 12 per cent disagree that they got fresh insight on how to work neatly and creatively.

The result of question 7 also shows that 16 per cent of the respondents strongly agree and 72 per cent agree while $<1$ per cent strongly disagree and 2 per cent disagree that they got a new perspective of using two or more software applications together to produce the required results. Specifically, the researcher wanted to know if individuals displayed the technical abilities needed to integrate between, different computer programs to perform the given tasks with ease or if newly learned while collaborating. In responding to question 8, 28 per cent strongly agree and 52 per cent agree while 4 per cent strongly disagree and 16 per cent disagree that the project enabled all the participants in each group to be focused on collective efforts rather than individual effort.

Question 9 shows participants' response to the level of responsibilities demonstrated by individuals within each group. A significant percentage of the students believe it is their individual responsibility to ensure that the group get the job done and if one fails, others fail. As a result, 32 per cent strongly agree and 64 per cent agree that it is the responsibility of each group member to see that the project succeeds. While 4 per cent strongly disagree and $<1$ per cent disagree.

Question 10 reflects participants' responses to the statement about the fact that a collaborative project allows the brainy students to help weaker students in the group to succeed. 
The results show 40 per cent strongly agree and 52 per cent agree with the statement. While $<1$ per cent strongly disagree and 8 disagree respectively. This shows a significant number of the respondents concurred with the statement.

Q9. Greater responsibility for myself and the group

Q10. Enable brainy learners to help weaker learners in the group

Q11. Gained useful and insightful knowledge during this exercise

Q12. Learners actively participated in the teaching and learning process

Q13. It was fun working on a project like this

Q14. Fostered team spirit

Q15. Waste of time explaining things to

Others

Q16. Difficult getting members to equally participate in tasks

Figure 2: Results of part two (questions 9 to 16)

All the participants responded positively with 36 per cent strongly agreeing and 64 per cent agreeing that they gained insightful knowledge during the execution of the project. This result shows that collaborative project is one of the best facilitation methods in facilitating design education. Sixteen per cent of the respondents strongly agree and 56 per cent agree that all the 
students actively participated in the teaching and learning process by engaging fully with the project while $<1$ per cent strongly disagree and 28 per cent disagree.

In responding to question 13, 32 per cent strongly agree, 64 per cent agree, <1 per cent strongly disagree and 4 per cent disagree that it was fun working on a project like this. This response reflects the level of the participant's social interaction during this exercise. A significant number of the students used this opportunity to build relationships with other students they could not ordinarily mixed or interact with and made the best out of it. The result also shows that 28 per cent strongly agree, 56 per cent agree, $<1$ per cent strongly disagree and 16 per cent disagree are the responses to the notion that the project fostered team spirit among the participants.

Question 15 reflects participants' response to whether time spent on explaining things amongst learners was a waste of time or not. Sixteen per cent strongly disagree while 56 per cent disagree that it was a waste of time. This means a significant proportion (72\%) were of the opinion that it is part of learning when you teach others or assist them to understand the concept in the brief given by the lecturer. Nevertheless, 12 per cent strongly agree while 16 per cent agree that, it was a waste of time explaining things that are not clear to the other members of the group.

Question 16 assesses the participants' feelings about equal participation of the group members. The results show a significant level of unhappiness about the commitments and involvement of some group members. Sixty-four per cent agree while the remaining 36 per cent disagree that it is difficult to get every member to participate equally. They were of the opinion that the workload was not divided equally within their group. Some felt that they were more active than the others were. From this result, it was deduced that it is difficult getting members to participate equally in collaborative works with practical tasks.

Question 17 shows the participants response about their whole experience and if they would be able to solve a similar problem in the near future. This result showed that having overcome all the challenges faced during the projects, 84 per cent believed that if they were confronted with similar projects, they would deliver. These respondents believed in themselves and the level of learning and knowledge they gained, while the remaining 16 per cent respondents thought they would not be able to handle such project. It shows there is a significant difference between the levels of the experiences and competencies gained by the students after the completion of the project.

Question 18 shows that 84 per cent of respondents associate the success of the projects to the fact that the needed materials were provided, unlike when they do individual projects and blame the late submission on non-availability of materials and lack of financial support. While 
the remaining 16 per cent assumed they could have achieved the same result if the institution did not supply the materials.

Q17.Will you be able to singularly handle a similar project in the Q18. If materials for group works are supplied by the department would it make any different in your outcomes Q19. What is the maximum group size you will recommend for a similar project? $\mathrm{G} 1=4$ group members G2= 5 group members G3= 6 group members G4= More group members Q20 Which part of the project process gave you more competencies? $C D 1=$ Conceptual development $C D 2=5$ group members $C D 3=6$ group members $C D 4=$ More group members

CW1 $=$ Computer work $C W 2=5$ group members CW3 $=6$ group members CW4= More group members

$C M 1=$ Construction and measurement $C M 2=5$ group members $C M 3=6$ group members CM4= More group members

GV1= Application of glue \& pasting of Vinyl (finishing) $G V 2=5$ group members GV3 $=6$ group members GV4= More group members

Q 21 Which part of the project process were morechallenging? $\mathrm{CH} 1=$ Conceptual development $\mathrm{CH} 2=$ Computer work $\mathrm{CH} 3=$ Construction and measurement $\mathrm{CH} 4=$ Application of glue \& pasting of the Vinyl (finishing)

$C P 1=$ Computer work
$C P 2=5$ group members
$C P 3=6$ group members
$C P 4=$ More group members
$C C M 1=$ Construction and measurement
$C C M 2=5$ group members
$C C M 3=6$ group members
$C C M 4=$ More group members

GPV1= Application of glue \& pasting of Vinyl (finishing) GPV2 $=5$ group members $G P V 3=6$ group members GPV4= More group members

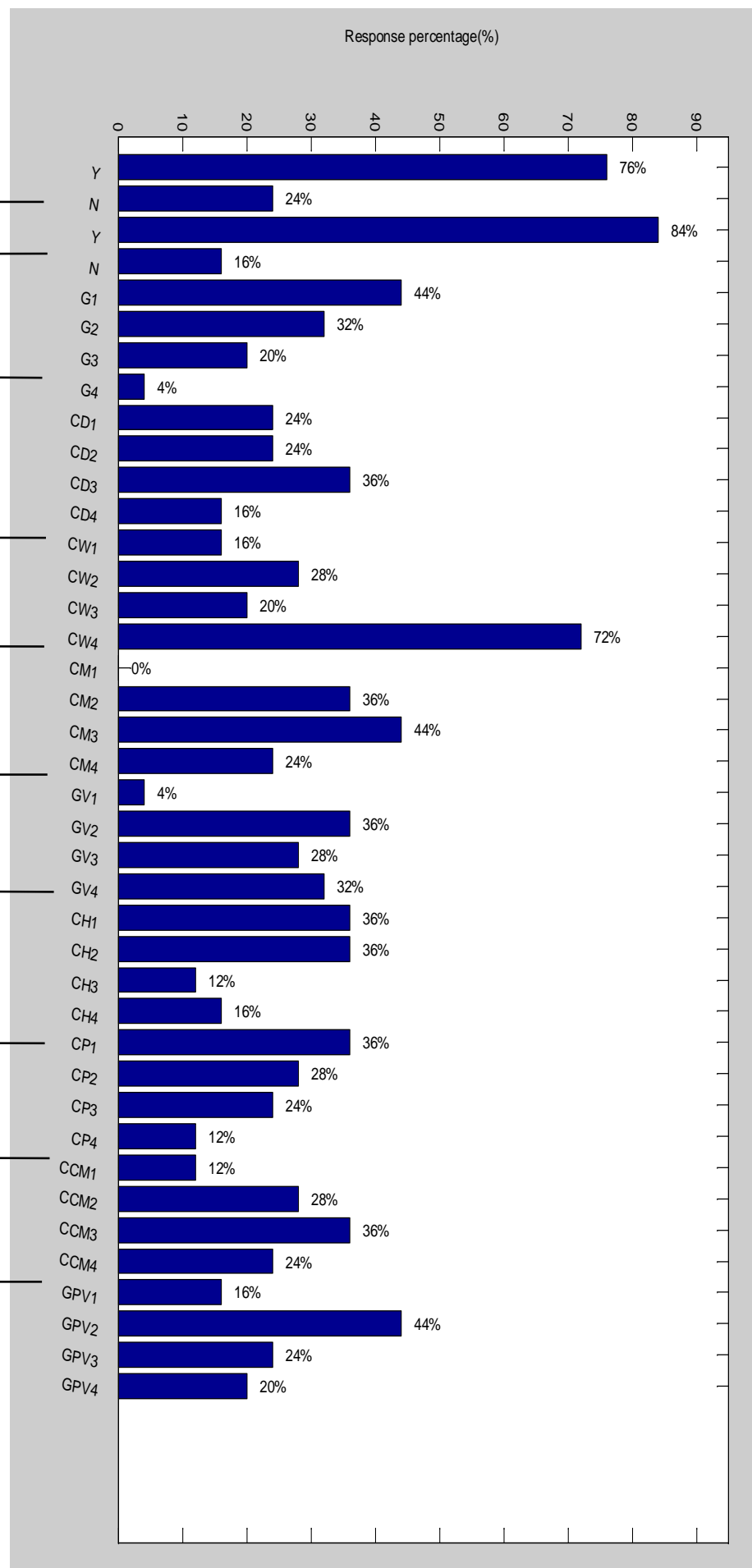

Figure 3: Results of part 3 (questions 17 to 21)

Question 19 reflects the participants' prefered the maximum number in a group. When participants were asked about how big or small the size of each group should be, the suggested 
numbers to be in each group in the questionnaire were as follows; G1 = 4 group members, G2 = 5 group members, G3 = 6 group members, G4 = more group members. Fourty-four per cent supported four members constituting one group, while 32 per cent suggeted five in each group. Twenty per cent said six members are ideal for one group and 4 per cent of the respondents think there should be more than six members in a group. Different opinions emanated from this question, which shows that only 4 per cent of respondents suggested more than six people in each group for a project of this magnitude.

In order to determine where the most learning took place in question 20, it is sub-divided into five sub-questions. All the sub-questions were meant to assess the level of knowledge and competencies gained in this collaborative learning exercise. As a result, the knowledge areas were also divided into four sub-questions. That is, (1) concept development, (2) computer work and printing, (3) constructions and physical measurements and (4) application of vinyl, gluing and finishing. The students were asked to assess their competencies and capabilities on a Likert scale ranging from one to four with one being the least and four being the highest level of learning that took place.

This result shows that 24 per cent of the respondent rated concept development as their lowest place where they gained competencies by rating the knowledge one out of four, meaning the value of innovative knowledge gained was 25 per cent. This shows they did not gain much in this sector. Another 24 per cent of the respondents rated this sector as their second least sector where they gained competencies. This set of respondents indicated average (50\%) in terms of value of the experiences gained. While 36 per cent believe the concept development section of the collaborative learning provided them with sufficient tasks that made them more proficient by scoring the level of their learning three out of four. This means they received 75 per cent learning in this category. While the remaining 16 per cent respondents believed this sector of learning gave them the highest level of competencies by scoring the learning that took place a score of four out of four, meaning the knowledge gained is 100 per cent.

The results also show that 53 per cent of the respondents believed this sector of learning gave them the highest level of competencies by scoring the learning that took place a score of four out of four, meaning the knowledge gained is 100 per cent. Fifteen per cent of the respondents rated computer work process as their second highest place where they gained competencies by rating the knowledge three out of four, meaning the value of knowledge gained was 75 per cent. This shows they gained much knowledge in this sector. Twenty-one per cent of the respondents rated this sector as their second least sector (2 out of 4 scores) where competencies were gained. This set of respondent gained just average (50\%) in terms of value 
of the gained knowledge. While 12 per cent believed the computer works section of the collaborative learning gave them the least competencies by scoring the level of their learning one out of four. This means they received 25 per cent learning in this category.

Furthermore, the results show that 23 per cent of the respondents believed the construction of the final 3D display sector of learning gave them the highest level of competencies by scoring the learning that took place a score of four out of four, meaning the knowledge gained is 100 per cent. Forty-two per cent of the respondents rated the construction of final 3D display process as their second highest place where they gained competencies by rating the knowledge three out of four, meaning the value of knowledge gained was 75 per cent. This shows they gained much knowledge in this sector. Thirty-five per cent of the respondents rated this sector as their second least sector (2 out of 4 scores) where competencies were gained. This set of respondents gained just average (50\%) in terms of value of the gained knowledge. While $<1$ per cent believed this knowledge sector of the collaborative learning gave them the least competencies by scoring the level of their learning one out of four. This means they received 25 per cent learning in this category.

It was also found that 32 per cent of the respondents thought gluing, vinyl application and finishing sector of learning gave them the highest level of competencies by scoring the learning that took place four out of four, meaning the knowledge gained is 100 per cent. Twenty-eight per cent of the respondents rated this finishing process as their second highest place where they gained competencies by rating the knowledge three out of four, meaning the value of knowledge gained was 75 per cent. This shows they gained much knowledge in this sector. Thirty-six per cent of the respondents rated this sector as their second least sector (2 out of 4 scores) where competencies were gained. These respondents gained just average (50\%) in terms of value of the gained knowledge. While 4 per cent believed this knowledge sector of the collaborative learning gave them the least competencies by scoring the level of their learning one out of four. This means, they received 25 per cent learning in this category of glueing and pasting of vinyl (finishing).

Question 21 is also sub-divided into five questions. All the subsidiary questions were meant to assess the challenges they face and how they were able to overcome the obstacles in this collaborative learning exercise. However, some students felt there were some hiccups when executing their group project as a whole. As a result, they believed it had a significant effect on their outcome as a group. Some of their comments are documented below:

We worked as a group, although some members were lazy and reluctant. We always put huge effort (Participant 1). 
It is good working under pressure, as it challenges the individuals in the group to put their different skills together in order to work at much faster rate by having each member focus on the task that they are good at (Participant 2).

The project helped us to identify each other's weakness and strength (Participant 3).

Some students had a different opinion and their comments about the project are positive. Their comments showed they enjoyed the project:

We worked very hard to complete the project on time and our individual effort paid off (Participant 4).

It was interesting, got to know people I wouldn’t generally talk to (Participant 5).

In the semi-structured interview part of the questionnaire, questions 22-23, the students were asked to comment on the project and reflect on their learning experience. The responses show that there is satisfaction with the learning experience amongst all the students. Some of their comments are as follows:

It was a nice creative project. Just wish we planned more (Participant 6).

It is amazing seen how patient, careful and steady one of my colleagues hands are while performing some of the tasks assigned to him. I wish we can have more of this because I learned a new practice from him (Participant 7).

It was a very innovative project which changed from time to time due to challenges (Participant 8).

The following comments portray some understandings of this learning method from students' responses to question 22 about their individual feelings about the project.

We were all so excited that we were going to produce the best thing we had ever done ... when everyone started to be art directors, supervisors and managers, there was no control and tensions started to build within our group (Participant 9).

Too many different ideas ... people wanting their own way and not listening to others and internal conflict (Participant 10).

These above statements demonstrated that there were conflicts and differences amongst each group. However, the lecturer informed the students beforehand that the success of one depends on others, as suggested by Smith (1996). Therefore, students were able to manage the problems before they influenced their learning experience and the outcomes.

When the participants were asked to reflect on their challenges during the learning activities in question 23, the participants' experiences are varied. Some participants appreciate working on such project while others find it difficult to use the opportunity to its maximum 
potential. To attest to that, some participants attributed working in groups in design field to irritation and frustration, because ample time was spent on dealing with different attitudes exhibited by some members, which directly or indirectly impacted on the outcome of their project. This is best shown and embodied in the participants' contradictory comments as follows:

We had problems with certain individuals because they are not used to generally working in a group and they wanted to work on their own (Participant 11).

Working in a group is hell. Having to work with people that don't have the same vision as you was also a problem. With all that said I am glad it's over (Participant 12).

Some students do not want to cooperate (Participant 13).

Some participants also thought their voices were not heard by their group members and felt that impacted their group performance. The following comments reflect the feelings of such participants.

I think our group would have done better if other students considered my 'problem solving' ideas (Participant 14).

Dealing with many different opinions and clashing on how to do things (Participant 15).

People couldn’t decide on what to do (Participant 16).

Working with like-minded people helps. It works better if everyone has a specific task, so everyone feels involved and no one can say they didn't have work to do (Participant 17).

Some participants expressed their dissatisfaction on the number of group members in each group. They thought there were too many people in each group and those respondents were of opinion that they could have better managed fewer members. Their comments were:

Some members were not always available (Participant 18).

When group members exceeded 4 learners it is difficult to make sure that everybody is giving an equal amount of effort and input (Participant 19).

Difficult to accurately measure individual's contribution/to equally share responsibilities (Participant 20).

One of the students responded as follows to question 24 about students' learning experience, 'There must be equal gender in each group'. Unfortunately, the demography of the class did not permit the equal distribution of the gender in each group. The class had more male (18) than female (10) students. Not only that, the selection method adopted by the lecturer partly depended on luck as only one student was seeded in each group. 


\section{COMPARISON OF ACADEMIC PERFORMANCE OF INDIVIDUAL STUDENTS DURING INDIVIDUAL COMPETITIVE PROJECT AND GROUP PROJECT}

The syllabus of DET20AK course stipulated that students must earn 50 per cent in order to pass the course and move on to the next level. Three final marks of individual students from a total number of nine previous projects were selected randomly and compared with the total marks scored by individual students. Significant differences in the individual marks were identified when compared with the group marks. This means that individual students' marks were better in group work than individual marks obtained in competitive individual projects. In addition, the gaps between the year marks of the top achieving students and the weaker students were significantly close. The results are impressive. This performance strengthens the students' overall year mark in this subject except for those who did not participate in the preliminary phase of the group project (See Figures 4, 5 and 6).

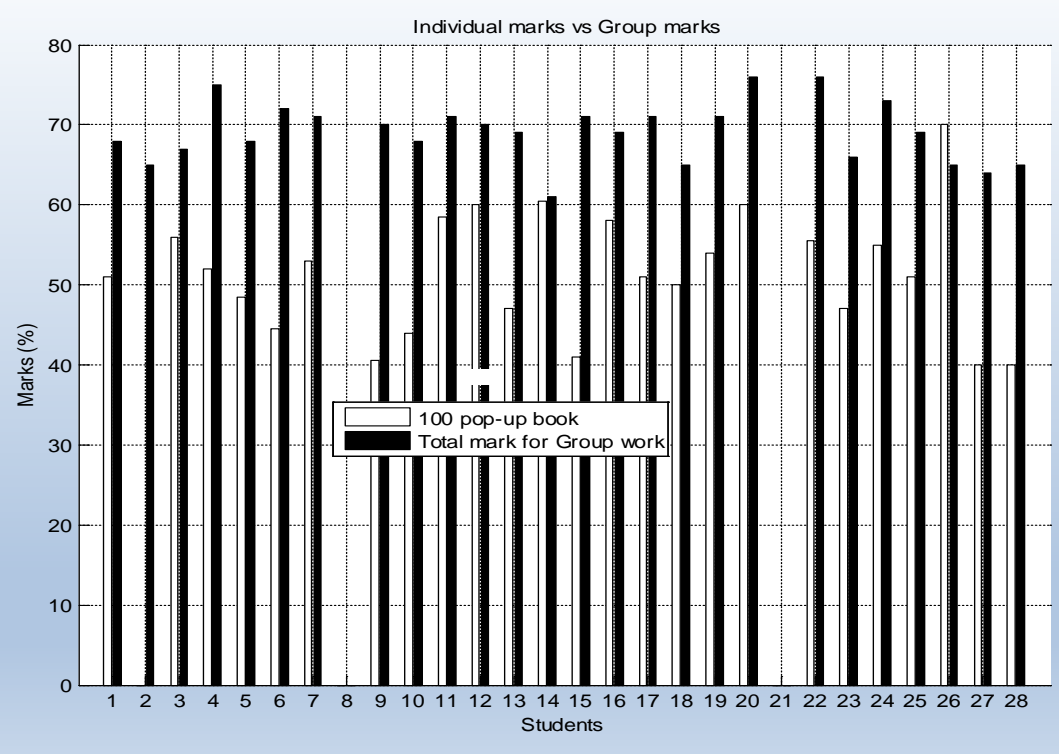

Figure 4: Differences between the individual marks obtained for designing a pop-up book in comparison with the total marks obtained by individuals for the group project 


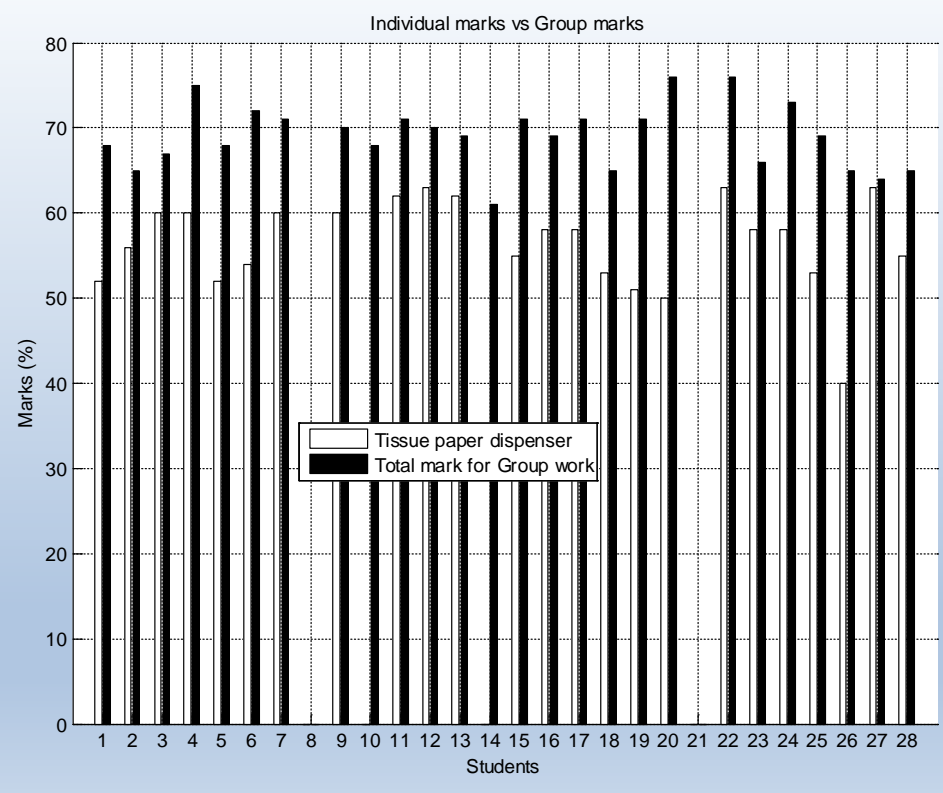

Figure 5: Differences between the individual marks obtained for making tissue paper dispensers in comparison with the total marks obtained by individuals for the group project

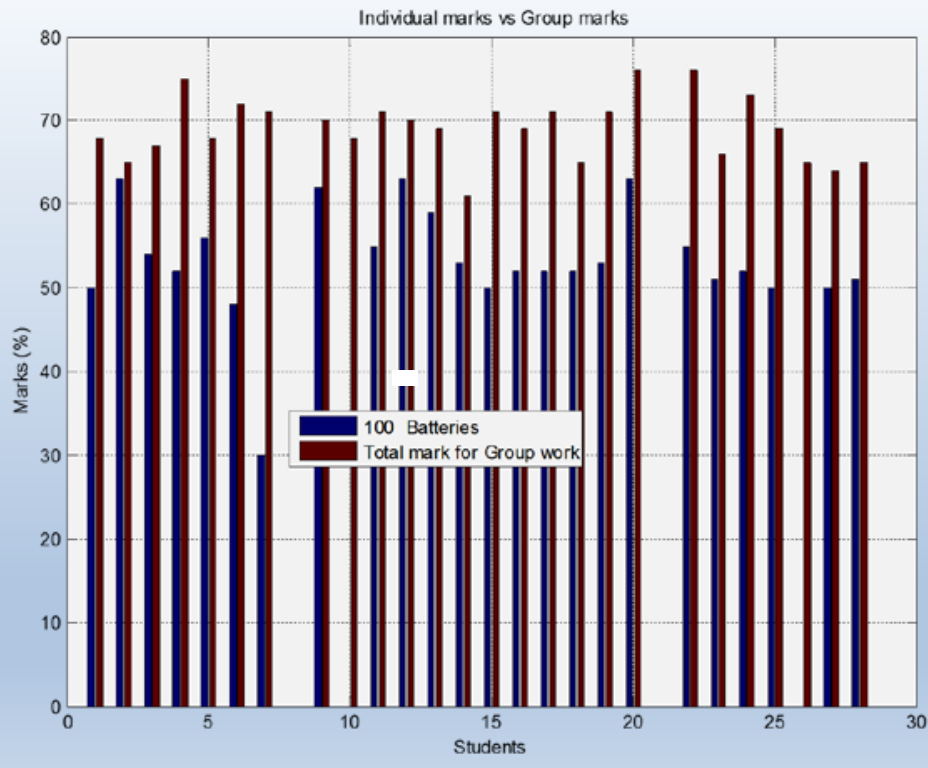

Figure 6: Differences between the individual marks obtained for product design (batteries) in comparison with the total marks obtained by individuals for the group project

\section{DISCUSSION AND IMPLICATIONS FOR PRACTICE}

The results of this study suggest that collaborative learning strategies in the design techniques course contribute to achievement of learning outcomes. This pedagogical approach enables students to gain knowledge in all the four learning categories based on basic skills as well as complex cognitive skills. Significantly, this study provides an innovative pedagogical model 
that combines collaborative design practice and a real-world project. Some students find it difficult to work in a group and others are concerned about unequal participation among group members. However, monitoring and constantly reminding students that one cannot succeed without others motivated them to work together for a common goal. As a result, learning took place, even though most of their prior learning in this course was implemented independently and competitively.

These projects afforded the students within the same group the opportunity to constantly interact with one another towards a common goal. Interactions between the students was consistently strong throughout the project process and all parties benefitted from the collaboration. Accordingly, graphic design students were generally ready to accept guidance and critiques from their peers, as well as the lecturers. What set these collaborative design projects apart from other graphic design projects are the adept outcome and the amount of control that the students are given over the design. Comments about positive aspects of the project included a sense of ownership demonstrated by students on 'real world' projects like these and the opportunity afforded them to execute finished ideas.

One of the lessons emerging from the discussion was that collaborative projects should not be assigned concurrently with other outstanding projects in the same subject because some students will use it as an excuse to perform below expectations in the group projects. These projects also gave the students opportunity to interact more than when working on individual projects. It provided learning action, which transpires as two or more students work on different subtasks within each group. One can also say that these learning actions have an effect upon one another. Significantly, through the collaborative framework, article contributes to a curriculum design model built on student's collaborative learning in groups.

The implications of this study for higher education in South Africa is that, based on the nature of this project and the learning in which students participated actively, is that competencies and confidence improved among students. Thus, the majority of students contributed to the project through collaborative learning. It is argued that collaboration learning method effective as previously found by Forrester and Tashchian (2010) in their studies. In addition, these findings affirm findings of previous research on collaboration that learning can take place among students, by actively engaging in learning as a result, promotes students learning not in the usual learning that takes place from lecturer to students alone (Singer, Marx, Krajcik and Clay Chambers 2000). 


\section{CONCLUSION}

This study found that effective collaborative learning in graphic design studies requires more than just grouping students and asking them to work together on a project. Conversely, we argue that there is a need for an appropriate, well-structured approach with well-designed tasks to guide students to the utmost learning outcomes. We further argue that it needs monitoring and a multiple assessment method that will assess the progress as well as the product. This learning method is based on the notion that learning is shared, thus group members work together with one another - talking and working through the learning process. Thus, there should must be an adequate monitoring scheme in place to assist students to attain the necessary outcomes otherwise some students may find it difficult to cope with the learning styles, attitudes and behaviours of others in the group, which could prevent the collaborative project from running efficiently.

Nonetheless, the students' responses indicated that the project indeed afforded opportunities to learn from their peers. Moreover, for the students knowing that the projects they are working on are 'real' was a wonderful feeling. Not only that, the students were fully involved in problem solving activities that enabled them individually, actively and collaboratively explore, experiment, research, create, reflect, discuss, critique and evaluate their learnings. This concur with Singer et al. (2000) which argues that curriculum design principles should attempt to engage students in activities that will make them reasoning, explain and debating their information.

In conclusion, this article provides an innovative pedagogical model that combines collaborative design practice and a real-world project.

\section{ACKNOWLEDGEMENT}

This study is part of the Scholarship of Teaching and Learning (SoTL) Project funded by the Department of Higher Education and Training (DHET) Teaching Development Grant (TDG) at the Central University of Technology, Free State.

\section{REFERENCES}

Bruffee, K. 1993. Collaborative learning. Baltimore: The Johns Hopkins University Press.

Cantwell, R. H. and B. Andrews. 2002. Cognitive and psychological factors underlying secondary school students' feelings towards group work. Educational Psychology 22(1): 75-90.

Choe, S. W. T. 2001. Analyzing scientific literature using a jigsaw group activity. Journal of College Science Teaching 30(5): 328-330.

Chiu, M. M. 2000. Group problem solving processes: Social interactions and individual actions. Journal for the Theory of Social Behavior 30(1): 27-50. 
Chiu, M. M. 2008. Flowing toward correct contributions during groups' mathematics problem solving: A statistical discourse analysis. Journal of the Learning Sciences 17(3): 415-463

Dillenbourg, P. 1999. Collaborative learning: Cognitive and computational approaches. Advances in learning and instruction series. New York, NY: Elsevier Science.

Enerson, D. M., R. N. Johnson, S. Milner and K. M. Plank. 1997. The Penn State Teacher II: Learning to teach, teaching to learn. University Park, PA: The Pennsylvania State University.

Forrester, W. R. and A. Tashchian. 2010. Effects of personality on attitudes toward academic group work. American Journal of Business Education 3(3): 35-45.

Francescato, D., R. Porcelli, M. Mebane, M. Cuddetta, J. Klobas and P. Renzi. 2006. Evaluation of the efficacy of collaborative learning in face-to-face and computer-supported university contexts. Computers in Human Behavior 22: 163-176.

Garland, R. 1991. The mid-point on a rating scale: Is it desirable? Marketing Bulletin 2: 66-70,

Gerlach, J. M. 1994. Is this collaboration? In Collaborative learning: Underlying processes and effective techniques, ed. K. Bosworth and S. J. Hamilton. New Directions for Teaching and Learning 59: 5-14.

Kagan, S. 1986. Cooperative learning and sociocultural factors in schooling. In Beyond language: Social and cultural factors in schooling language minority students. LA: Evaluation, Dissemination and Assessment Center, California State University, Los Angeles.

Lozano, M., E. Garcia-Cueto and J. Muniz. 2008. Effect of the number of response categories on the reliability and validity of rating scales. Methodology. European Journal of Research Methods for the Behavioral and Social Sciences 4(2): 73-79.

MacGregor, J. 1990. Collaborative learning: Shared inquiry as a process of reform. In The changing face of college teaching, ed. M. D. Svinicki. New Directions for Teaching and Learning, no 42. San Francisco: Jossey-Bass.

Singer, J., R. W. Marx, J. Krajcik and J. Clay Chambers. 2000. Constructing extended inquiry projects: Curriculum materials for Science Education reform. Educational Psychologist 35(3): 165-178. http://dx.doi.org/10.1207/S15326985EP3503_3

Slavin, R. E. 1987. Cooperative learning - Theory, research and practice. Englewood Cliffs, NJ: Prentice Hall.

Smith, K. A. 1996. Cooperative learning: Making 'groupwork’ work. In Active learning: Lessons from practice and emerging issues, ed. C. Bonwell and T. Sutherlund. New Directions for Teaching and Learning 67: 71-82. San Francisco: Jossey-Bass.

South African Qualification Authority. 2005. The National Qualifications Framework and Curriculum 2005. http://qspe.saqa.org.za/showQualification.php?id=49603 